\title{
Guidance on gastrointestinal surveillance for hereditary non-polyposis colorectal cancer, familial adenomatous polypolis, juvenile polyposis, and Peutz-Jeghers syndrome
}

\section{G Dunlop}

W ithin groups of patients with colorectal cancer who report a family history of cancer, it is possible to identify cases associated with defined genetic susceptibility syndromes. These syndromes account for a small, but appreciable, proportion of all cases of colorectal cancer and are characterised by very high absolute cancer risk. There is usually evidence of germline transmission of a dominant gene associated with bowel cancer susceptibility, but there is frequently an excess of other cancer types in the family. Genes responsible for these syndromes have been identified, although some families have been identified where linkage to all known genes has been formally excluded. Hence, it is likely that there are other dominant genes that have yet to be identified. This implies that at risk people can be identified in two ways; empirically on the basis of family history or clinical and pathological criteria, or by molecular analysis of the respective gene. Although there are other rare syndromes associated with colorectal cancer risk, in the interests of clarity this guideline is restricted to discussion of hereditary non-polyposis colorectal cancer (HNPCC), familial adenomatous polyposis (FAP), juvenile polyposis (JP), and Peutz-Jeghers syndrome (PJS). The syndromes are defined and summarised in Online Inheritance in Man (OMIM), for which the OMIM ID numbers are given for each syndrome and the respective URL in the appendix.

The molecular aetiology for each of these syndromes is listed in appendix 1. It has been shown that some people who carry pathogenic mutations of one of the causative genes do not have a strong family history of colorectal cancer. Hence, it is essential to define people at risk either by family history that fulfils inclusion criteria or those carrying a mutation in the respective gene. Screening and surveillance issues for these families must be considered separately from that recommended for people fulfilling low to moderate risk guidelines (see separate guidance). Cancer risk for members of such families is many times greater than that attributable to low penetrance alleles. This should be reflected in qualitative differences in management of such people and should address differences in the degree of cancer risk.

This document aims to provide guidance for clinical surveillance and management of the gastrointestinal tract in each of these scenarios, using currently available data to assess the evidence base for each recommendation. It is not intended that this guidance should comprise a comprehensive management plan for all aspects of these complex genetic disorders. No discussion is provided on the need for extraintestinal surveillance. The reader should be aware of the risk of other malignancies and should consult specific specialist literature for advice on control of extra-intestinal cancer risk where appropriate.

\section{EXECUTIVE SUMMARY}

(1) People with a greatly increased risk of gastrointestinal malignancy on the basis of inheritance of a single gene disor- der can be identified on the basis of family history and clinicopathological features. The risk of cancer ranges from $10 \%$ to $100 \%$ in the syndromes that are the focus of this guidance. Families can be defined by observation of classic features of the respective syndrome. However, as the causative genes have been identified for most families with these syndromes, it is increasingly possible to define at risk people by molecular analysis. This guidance specifically excludes people whose family history does not fulfil inclusion criteria or who do not carry a germline mutation in the respective gene. Recommendation Grade: $B$

(2) Patients who, on the basis of clinical criteria, have been diagnosed as being affected by one of the syndromes that are the focus of this guidance should be referred to the Regional Genetics Centre for formal counselling and mutation analysis of the respective gene. Members of families where a causative gene mutation has already been identified should be referred to the respective Regional Genetics Centre for formal counselling and predictive gene testing. There is no indication for continued surveillance of family members who do not carry the mutation that has been shown to be causative in other affected members of the family. Hence, a negative gene test from an accredited genetics laboratory in families with characterised mutations means that gastrointestinal surveillance should cease. Recommendation Grade: B

(3) The cancer risk associated with HNPCC, FAP, JP, and PJS is discussed and the rationale for surveillance is rehearsed. The weight of evidence in support of surveillance and the frequency of surveillance is discussed for each syndrome. Recommendation Grade: B

(4) The place of prophylactic surgery is discussed in the context of surveillance and the evidence for benefit discussed. The rationale of prophylaxis in FAP is best established, but the nature of the surgery remains under debate. Recommendation Grade:B

(5) The place of extracolonic gastrointestinal surveillance is discussed for each syndrome. Available evidence supporting recommendation for upper gastrointestinal surveillance is much weaker than for colorectal intervention. Recommendation Grade: C

\section{DEFINITION AND AETIOLOGY}

The syndromes discussed here can be defined by molecular aetiology, as mutations have been identified in causative genes for a substantial proportion of cases previously only defined by clinicopathological criteria. It is possible that there are genetic and/or environmental modifiers of the phenotype and there is

Abbreviations: HNPCC, non-polyposis colorectal cancer; FAP, familial adenomatous polyposis; JP, juvenile polyposis; PJS, Peutz-Jeghers syndrome 
already some evidence for this in HNPCC and FAP. However, modifiers and gene-environment interactions are not discussed here.

\section{HNPCC (OMIM 114500, 120435, and 120435)}

HNPCC is an autosomal dominant genetic disorder resulting from mutation of one of five DNA mismatch repair genes and is characterised by markedly increased cancer risk consequent upon inheritance of a mutation. The disorder can be defined empirically by family history or by demonstration of a pathogenic mutation in one of the DNA mismatch repair genes.

To partition a group of families that were highly likely to carry dominant genes, the International Collaborative Group on HNPCC empirically defined HNPCC. ${ }^{1}$ The original definition has been modified to encompass the excess risk of endometrial cancer. As a result, HNPCC is now defined as three or more family members affected by colorectal cancer or $\geqslant 2$ with CRC and one with endometrial cancer in $\geqslant 2$ generations; one affected relative must be age $\leqslant 50$ at diagnosis; one of the relatives must be a first degree relative of the other two. $^{23}$ As the causative genes have been identified ${ }^{45}$ (ICG database), fulfilment of these criteria is not an absolute requirement for classification as HNPCC, because gene carriers affected by colorectal cancer have been identified who have a much lesser degree of family history. ${ }^{6}$ Nonetheless, the criteria do serve to enrich for families with causative mutations in DNA mismatch repair genes. ${ }^{7}$ Lesser degree of family history is associated with a lower proportion of cancer cases carrying mutations in one of the known DNA mismatch repair genes. ${ }^{6-8}$ However, an appreciable proportion of early onset colorectal cancer is attributable to DNA mismatch repair gene mutations. ${ }^{69}$ This should be borne in mind when managing young patients with colorectal cancer, as they may be obligate gene carriers, even without an obvious family history.

The lifetime gastrointestinal cancer risk associated with HNPCC is variously reported as around $80 \%$ for colorectal cancer and $13 \%-20 \%$ for gastric cancer in studies that have selected families by HNPCC criteria. ${ }^{10}{ }^{11}$ This compares with $74 \%$ colorectal cancer risk for men and 30\% risk for women where attempts have been made to carry out systematic analyses. ${ }^{12}$ It should be noted that people who have not been gene tested within HNPCC families but who have an affected parent, are at $50 \%$ of the risk documented gene carriers, because a dominant gene is involved. The cumulative risk of colorectal cancer in each of these categories is substantially greater than for low to moderate people discussed elsewhere in the respective guidance.

\section{FAP (OMIM 175100)}

FAP is an autosomal dominant syndrome with near complete penetrance, characterised by the presence of more than 100 adenomatous polyps of the colon and rectum. ${ }^{13}$ The condition is attributable to truncating mutations of the APC gene on chromosome 5q (APC mutation database) and causative mutations can be identified in about $60 \%$ of families. ${ }^{15}{ }^{16}$ The remainder are linked to APC but the mutations cannot be identified for technical reasons. There is no evidence of genetic heterogeneity in families with classical dense polyposis or those fulfilling the criteria of $>100$ adenomatous polyps. However, there is evidence of phenotypic heterogeneity with some mutations being associated with a severe phenotype and others being associated with a mild, attenuated phenotype and relatively few polyps. ${ }^{17}$ The development of large bowel cancer is virtually certain without prophylactic surgery ${ }^{14}$ and the risk of cancer developing in gastroduodenal polyposis is about 7\%. ${ }^{1311819}$ Around 25\% of all cases are attributable to new (sporadic) mutations in the APC gene and consequently there is no family history in such cases. ${ }^{20}$

\section{PJS (OMIM 175200)}

PJS is an autosomal dominant syndrome with high penetrance, defined by the presence of hamartomatous polyps of the small intestine, colon and rectum, in association with mucocutaneous pigmentation. ${ }^{21}{ }^{22}$ The risk of colorectal cancer is $10 \%$ to $20 \%{ }^{21}{ }^{23} 24$ In $20 \%-63 \%$ of cases, inactivating mutations can be identified in the gene STKll(LKBl).25-27 There is evidence for genetic heterogeneity with LKBl involvement being formally excluded in some families. ${ }^{26}$

\section{JPS (OMIM 174900 and 601228)}

JPS is defined by the presence of multiple typical hamartomatous polyps of the colon and rectum. The condition usually manifests during childhood but definition of the condition is confounded by the occurrence of isolated juvenile type polyps in children. These lesions are probably attributable to somatic mutation in the gene responsible. However, single juvenile type polyps do not seem to be associated with excess cancer risk..$^{28}$ In contrast juvenile polyposis is associated with a colorectal cancer risk of around $10 \%-38 \%$ and a gastric cancer risk of $21 \% .^{29}{ }^{30}$ In around $50 \%$ of cases, mutation of the SMAD4 gene can be identified. ${ }^{31-34}$ There is some evidence for genetic heterogeneity 35 and mutations have been identified in the BMPRlA gene. One study identified mutations in the PTEN gene36, although it is possible that the families studied may have actually have had Cowden's Disease, another rare syndrome associated with gastrointestinal polyposis.

\section{FREQUENCY \\ HNPCC}

The frequency of HNPCC can be estimated in two ways, depending on the definition. Using empirical criteria, ${ }^{2}$ $1 \%-2.4 \%$ of all cases of colorectal cancer fulfil HNPCC criteria. ${ }^{37-39}$ The proportion of colorectal cancer cases attributable to mutations in DNA mismatch repair genes is $2 \%-3 \% .^{9041}$ It is also possible to determine the carrier frequency of mutations in DNA mismatch repair genes and the estimated population carrier frequency is $1: 3139 .{ }^{41}$ There are no studies that have directly assessed the population frequency of people who report a family history that fulfils HNPCC criteria. However, segregation analysis suggests that dominant gene(s) with $63 \%$ penetrance has a population frequency of $1: 167 .^{42}$ This is 20 times greater than the estimated MMR gene carriage rate and it seems implausible that a family history conducive with HNPCC would be reported by l:265 of the population allowing for gene penetrance. Hence, a carrier frequency of 1:3139 is preferred for estimation of the surveillance workload.

FAP

The frequency of FAP in the general population is $1: 13528^{2043}$ whereas the presence of FAP in colorectal cancer incident cases is currently only $0.07 \% .{ }^{43}$ As registries improve detection of at risk family members, the proportion of colorectal cancer cases attributable to FAP should reduce, limited only by the proportion due to new mutations. People with new mutations do not have a family history and so tend to present later with symptoms.

\section{PJS and JP}

Because both of these conditions are rare, there are no reliable estimates of the frequency of PJS or JPS in index colorectal cancer cases or in the general population. However, less than $0.01 \%$ of colorectal cancer are attributable to these conditions. The population prevalence of PJS is probably around 1:50 000, ${ }^{21}$ and is probably similar to that of JP. However, one study in Jordan estimated the incidence rate of juvenile polyps was at least 1.4/100 000 and 0.03/100 000 for multiple juvenile polyps, which are those most associated with cancer risk. ${ }^{44}$ It is 
clear that both conditions are rare and so will not have a major effect on provision of surveillance.

\section{INTERVENTION \\ HNPCC}

Establishment of HNPCC Registries

- HNPCC families should be registered in Regional Clinical Genetics Centres and family members offered counselling. ${ }^{45}$ Ideally there should be specific HNPCC Registries. In many UK centres there is the option of mutation testing. Follow up of family history is an important function of registries, as self reported family history is not $100 \%$ accurate.$^{46}{ }^{47}$ Registries have been shown to improve structured delivery of management, to monitor interventions and surveillance as well as serving as a focus for audit. ${ }^{38}{ }^{48-50}$ Recommendation Grade: C

\section{Large bowel surveillance for HNPCC family members and/or MMR gene carriers}

- Biennial total colonic surveillance should start at age 25 years, or five years less than the first cancer case in the family, whichever is the earlier. Surveillance should continue to 75 years or until the causative mutation in that family has been excluded. Recommendation Grade: B

People with MMR gene mutations and people from Amsterdam positive HNPCC families should be offered surveillance of the colon. This is best achieved by colonoscopy, as the risk of polyps and cancer is high and a substantial proportion of patients have neoplasia restricted to the proximal colon. ${ }^{51-53}$ Incomplete colonoscopy should be followed by a completion barium enema soon after the failed colonoscopy. Flexible sigmoidoscopy and barium enema surveillance is another valid approach to surveillance, but would require colonoscopy for cases where lesions were identified. Surveillance should be offered biennially from the age of 25 years, or five years less than the age of onset of the first case in the family, whichever is the earlier. The support for starting surveillance at 25 years is not strong as there are no trials, but observational data indicate that the risk increases substantially from this age in family history defined groups ${ }^{11} 52$ and in mutation defined groups. ${ }^{125455}$ Screening interval should be from one to three yearly, but two yearly or more frequently is recommended as interval cancers have been observed at 18 months in one surveillance programme. ${ }^{56}$ There are no prospective randomised controlled trial data, but there is strong indirect evidence that surveillance provides a beneficial effect on both mortality and cancer incidence. ${ }^{51}$

\section{Colorectal surgery as prophylaxis and for established cancer in HNPCC family members and/or MMR gene carriers}

- Patients with an established colorectal malignancy and who are from an HNPCC family or known to carry a mutation in an MMR gene should be counselled and offered a surgical procedure that includes both a cancer control element and prophylaxis. At present there are no data supporting, or against, offering primary prophylactic surgery for patients who do not yet have cancer. Recommendation Grade: C

People with MMR gene mutations or those from Amsterdam positive HNPCC families who have cancer will require resectional surgery unless treatment is deemed as palliative. The risk of metachronous colorectal cancer is high ${ }^{57}$ and so there is substantial rationale in offering an element of prophylaxis to the cancer resection. For patients with proximal tumours, then colectomy and ileorectal anastomosis is a good option and facilitates surveillance of the retained rectum. ${ }^{58}$ The risk of cancer in the retained rectum is 3\% every three years for the first 12 years and so endoscopic surveillance of the rectum is mandatory after abdominal colectomy. ${ }^{59}$ This recommendation is partly on the basis that surveillance does not completely prevent cancer development ${ }^{51}$ and also that interval cancers are described on surveillance programmes. ${ }^{56}$ At present there are insufficient data to recommend for or against primary prophylactic surgery in MMR gene carriers, and so this must be on the basis of discussion with a fully informed patient and clinician. The balance of risk is not in favour of prophylactic surgery in at risk HNPCC family members (that is, not proven gene carriers), as the maximum colorectal cancer risk is $40 \%$ for men and $15 \%-30 \%$ for women.

Upper gastrointestinal surveillance for HNPCC family members and/or MMR gene carriers

- In families where there are cases of gastric cancer, biennial upper gastrointestinal endoscopy should commence at age 50 years, or five years less than the first gastric cancer case in the family, whichever is the earlier. Surveillance should continue to 75 years or until the causative mutation in that family has been excluded. Recommendation Grade: C

This recommendation is based on observations that some HNPCC families have a particular propensity for gastric cancer. ${ }^{1157}$ There are no studies of gastric surveillance in HNPCC and no reported observational data. However, it seems reasonable to offer upper gastrointestinal endoscopy contemporaneously with colonoscopy after the age of 50 years as the greatest increase in risk occurs at this age.

\section{FAP}

\section{Establishment of FAP Registries}

FAP families should be registered in Regional Clinical Genetics Centres and family members offered counselling. Ideally there should be specific FAP Registries. Throughout the UK there is now the option of mutation testing, which permits identification of gene carriers and also avoid unnecessary surveillance in non-carriers. FAP Registries have been shown to improve outcomes by structured delivery of management, monitoring interventions and surveillance as well as serving as a focus for audit. ${ }^{43}{ }^{60}$ Recommendation Grade: B

Large bowel surveillance for FAP family members

In a minority of FAP families a mutation cannot be identified and so annual flexible sigmoidoscopy should be offered to at risk family members from age 13-15 years until age 30, and at three to five year intervals thereafter until age 60 years. Surveillance might also be offered as a temporary measure for people with documented APC gene mutations but who wish to defer prophylactic surgery for personal reasons. Such people should be offered six monthly flexible sigmoidoscopy and annual colonoscopy but surgery should be strongly recommended before 25 years. After colectomy and ileorectal anastomosis, the rectum must be kept under review at least annually for life because the risk of cancer in the retained rectum is $12 \%-29 \% .{ }^{16162}$ The anorectal cuff after restorative proctocolectomy should also be kept under annual review for life.

Recommendation Grade: B

Individual patients can be defined as affected by FAP by demonstration of multiple adenomatous polyps or the presence of an APC mutation. In a minority of cases, a mutation may not be identified in an affected family member. Hence identification of gene carriers relies on clinical surveillance, in a manner similar to that used before the availability of mutation analysis. ${ }^{43}$ In cases where a mutation is identified, surgery is recommended (see below) but some patients may wish to defer surgery around important educational episodes. The patient must be counselled about cancer risk and offered intensive surveillance. These recommendations are based on indirect data before widespread mutation testing. ${ }^{134360}$ It is clear that large numbers of polyps is associated with a high risk of cancer ${ }^{63}$ and patients with large numbers of polyps early in life should be dissuaded from delaying surgery. 


\section{Prophylactic colorectal surgery}

- Patients with FAP should be advised to undergo prophylactic colectomy between the age of 16 and 20 years. The operation of choice is proctocolectomy and ileoanal pouch, in view of the long term risk of rectal cancer. However, colectomy and ileorectal anastomosis remains a useful option for many patients with relatively few polyps. Recommendation Grade: B

Although surgical management is not the focus of this guidance, mention is made here to put surveillance in the context of ultimate outcome. People with proven FAP require prophylactic surgery to remove the majority of at risk large bowel epithelium. In light of growing evidence that the risk of cancer in the retained rectum lies in the range $12 \%-29 \%$, ${ }^{626} 64$ the optimal procedure is restorative proctocolectomy with ileoanal pouch. However, colectomy and ileorectal anastomosis has a place in the management of some patient groups. ${ }^{656} \mathrm{It}$ is clear that identification of cases and prophylactic surgery has improved survival in FAP. ${ }^{18} 4360$

\section{Upper gastrointestinal surveillance in FAP}

- To combat the substantial risk of upper gastrointestinal malignancy in FAP after prophylactic colectomy, upper gastrointestinal surveillance is recommended. While the presence of gastroduodenal polyposis is well recognised, there are few published studies on which to gauge the potential benefit of surveillance. However, the approach seems reasonable and three yearly upper gastrointestinal endoscopy is recommended from age 30 years with the aim of detecting early curable cancers. Patients with large numbers of duodenal polyps should undergo surveillance yearly.

\section{Recommendation Grade: B}

Gastroduodenal and periampullary malignancy account for a small but appreciable number of deaths in FAP patients. ${ }^{13}{ }^{18} 19$ The overall lifetime risk of periampullary cancer is $3 \%-4 \%{ }^{67-69}$ and so the notion of upper gastrointestinal surveillance seems appealing. However, polypectomy is unsatisfactory $^{70}$ and almost all FAP patients will have some abnormality on inspection and biopsy of the duodenum. ${ }^{68}$ However, a decision analysis ${ }^{69}$ suggests some benefit to surveillance, although there remains concern about small numbers of end points and the uncertainty about the potential long term detrimental effect of major pancreaticoduodenal resection. None the less, it seems reasonable to offer three yearly upper gastrointestinal surveillance from age 30 and more frequently if there is extensive polyposis.

\section{PJS}

\section{Colorectal surveillance}

- Large bowel surveillance is recommended at three year intervals from age 18 years. The intervention should visualise the whole colon and so colonoscopy or flexible sigmoidoscopy with barium enema are appropriate. Recommendation Grade: C

The syndrome is rare and so experience is limited, underlined by the fact that available evidence comes from pooled descriptive experiences. None the less, it is clear that there is a substantial increase in overall cancer risk and colorectal cancer risk in particular for affected people. ${ }^{21-24}$ Often patients are diagnosed on clinicopathological grounds only and so cases may be overdiagnosed, leading to inaccuracy in the overall estimation of cancer risk. Pooled data on lifetime risk of colorectal cancer indicate a risk in the range 10\%-20\% and so by inference it seems reasonable to offer large bowel surveillance. However, it must be emphasised that there is no available evidence to indicate that this policy is actually beneficial.
Upper gastrointestinal surveillance

- Upper gastrointestinal surveillance is recommended at three year intervals from age 25 years. Recommendation Grade: C

There is an increased risk of gastric malignancy in PJS amounting to around $5 \%-10 \%{ }^{21-24}$ Although the clinical features are of small bowel polyps causing symptoms, pooled case series indicates that small intestinal cancer is rare. ${ }^{22}$ It seems reasonable to offer upper gastrointestinal endoscopy at three year intervals from age 25 years in view of the age distribution of published cases of gastroduodenal cancer. ${ }^{22}$

\section{JP}

\section{Colorectal surveillance}

- Large bowel surveillance for at risk people is recommended at intervals of one to two years from age 15-18 years or even before if the patient has presented with symptoms. Screening intervals could be extended at age 35 years in at risk individuals. However, documented gene carriers or affected cases should be kept under surveillance until age 70 years and prophylactic surgery discussed. The intervention should visualise the whole colon and so colonoscopy or flexible sigmoidoscopy with barium enema are appropriate. Recommendation Grade: C

Although isolated juvenile polyps are relatively common, JP is rare and consequently experience is limited. There are very few large descriptive studies, and no comparative studies to demonstrate potential benefit. None the less, there is a substantial risk of colorectal cancer amounting to $10 \%-$ $38 \%{ }^{29}{ }^{30}$ Many polyps are located in the right $\operatorname{colon}^{30}$ and so the whole colon should be visualised. There is particular risk of malignancy in cases where there is adenomatous element to the polyps. Hence, polyps should be snared and sent for histological examination. Consideration should be given to prophylactic surgery in cases with multiple polyps that cannot be controlled by snaring, those with symptoms, those with adenomatous change, and those where colorectal cancer is a feature of the family history.

\section{Upper gastrointestinal surveillance}

- Upper gastrointestinal surveillance is recommended at intervals of one to two years from age 25 years, contemporaneously with lower gastrointestinal surveillance. Recommendation Grade: C

The risk of gastric and duodenal cancer in JPS is around $15 \%-21 \% .{ }^{29}{ }^{30}$ Hence by inference it seems reasonable to offer surveillance. However, there are no data to support this approach and uncertainty about the potential benefits should be relayed to the patient.

\section{COSTS AND BENEFITS}

For the purposes of estimating the cumulative risk of serious complication for each of these conditions after polypectomy, available data on complications after colonoscopic polypectomy were used. ${ }^{71-74}$ The risk of colonoscopy without polypectomy is ignored. Published data indicate that the perforation rate after polypectomy is 22 (95\% CI 13.8 to 33.3 ) per 10000 and post-polypectomy bleeding occurs in a further 89 (95\% CI 71.5 to 109.5$)$ per 10000 . Mortality after polypectomy is 3.9 (95\% CI 1.1 to 8.8 ) per $10000,{ }^{71-74}$ although most fatalities arise in older patients.

\section{HNPCC}

Cancer risk is very high in HNPCC and there is substantial evidence from comparative studies to indicate a beneficial effect of surveillance benefit in incidence reduction and also in terms of mortality reduction. ${ }^{51}$ In one well controlled study, there was a $62 \%$ lower cancer incidence in gene carriers than 
in unscreened controls. Five year survival in carriers who were screened was $100 \%$, compared with $54 \%$ for those who were not screened. Surveillance seems to provide an average of seven years extra life for HNPCC family members. ${ }^{66}$

Annual caseload can be estimated for MMR gene carriers or people at 50\% risk within families fulfilling HNPCC criteria for a population of 300000 ( 150000 within the screening age group) served by a district general hospital. As HNPCC alleles are dominant, population frequency is $1: 3139$, implementing a biennial colonoscopy strategy would require 48 colonoscopies per annum at a cost of $£ 7200$. The cost per life saved is $£ 14925$, which compares very favourably with all current population cancer screening strategies. Furthermore, because of the high cancer risk, the cost of not offering surveillance intervention substantially exceeds that of offering the surveillance. ${ }^{66}$

Based on available data an estimate can be made of the cumulative risk of adverse effects attributable to biennial colonoscopy and polypectomy for gene carriers over 25 years of surveillance. In the best available long term analysis of surveillance experience for gene carriers, ${ }^{51}$ there were a total of 25 polypectomies in 85 gene carriers over 15 years. Thus, assuming the same rate of polypectomy over 25 years, an average of 13 colonoscopies and 0.49 polypectomies would be performed for each gene carrier. Using the complication rates discussed in the previous paper of this guidance, the cumulative 25 year risk is $1.3 \%$ for perforation, $0.4 \%$ for bleeding and $0.1 \%$ risk for intervention related death. These risks should be seen in the context of the $62 \%$ reduction in colorectal cancer incidence and $66 \%$ mortality reduction achievable by such surveillance. ${ }^{51}$ Thus, there is a substantial balance of benefit in favour surveillance compared with dealing with cancer as it arises on an expectant basis. None the less, it is important that at risk people are counselled as to cumulative dangers of a long term surveillance programme.

\section{FAP}

The workload associated with management of FAP families has already been absorbed into clinical practice. The condition is so highly penetrant and the cancer risk so high that it is difficult to anticipate any change in resource implications for FAP consequent upon introduction of these guidelines. However, rationalisation of management and surveillance may actually serve to reduce morbidity as well as costs.

It is clear that there is substantial benefit associated with identification of families and offering surveillance. ${ }^{43}{ }^{60}$ Survival in unscreened people is only $50 \%$ of groups kept under surveillance. ${ }^{43}$ Within a population of 300000 served by a district general hospital, there are an estimated 22 cases of FAP, most of these will already have undergone prophylactic surgery. Hence, there may be a maximum of two or three patients at any one time who require colorectal surveillance. The costs are small and the rationale for surveillance in at risk people overwhelming. The risks are small because the period of surveillance is short and so can effectively be ignored. Upper gastrointestinal surveillance will frequently not be undertaken at present and so these guidelines will increase workload, notwithstanding that benefit is unproven, as discussed above. However, the numbers remain small, with only an extra five to six upper gastrointestinal endoscopies required per year. The workload of flexible endoscopy of retained rectum will depend on the proportion of patients undergoing colectomy and ileorectal anastomosis but cannot be more than five to six per year.

\section{PJS and JP}

These disorders are considered together in view of similar population frequency, similar uncertainty about the value of surveillance and similarity in the degree of cancer risk. Taking both together, there are likely to be 12 cases and at risk people in a population of 300000 served by a district general hospital. Hence, a maximum of only six extra colonoscopies and six upper gastrointestinal endoscopies would be required. The benefits of surveillance are uncertain but the cancer risk is high and so it seems reasonable to suggest that surveillance should be offered. The aim is to identify cases at high risk of cancer and offer prophylactic surgery or resection for cancer at an early stage. In this respect, data showing that surveillance and proactive management of FAP should be considered relevant (see above).

As there is a high prevalence of colorectal polyps in these groups, it is important to note that the risk of polypectomy will

Appendix 1 Genes responsible for defined genetic syndromes predisposing to colorectal cancer

\begin{tabular}{|c|c|c|c|}
\hline Syndrome & & $\begin{array}{l}\text { Mutations } \\
\text { identifiable }\end{array}$ & Genes involved \\
\hline \multicolumn{4}{|c|}{ Hereditary non-polyposis colorectal cancer (HNPCC) (OMIM 1 14500, 120435, and 120435) } \\
\hline OMIM web pages & $\begin{array}{l}\text { http://www.ncbi.nlm.nih.gov/entrez/dispomim.cgi?id=114500, } \\
\text { http://www.ncbi.nlm.nih.gov/entrez/dispomim.cgi?id=120435 } \\
\text { http://www.ncbi.nlm.nih.gov/entrez/dispomim.cgi?id=120436 } \\
\text { http://www.nfdht.nl/database/mdbchoice.htm }\end{array}$ & & \\
\hline \multirow{2}{*}{\multicolumn{2}{|c|}{$\begin{array}{l}\text { Families fulfilling "Amsterdam" criteria } \\
\text { Looser definition families }\end{array}$}} & $80-90 \%{ }^{775}$ & hMSH2, hMLH1, \\
\hline & & $30-45 \%{ }^{876}$ & hMSH6, hPMS1, \\
\hline \multirow{2}{*}{ Early age of onset (+/- family history) } & $<30$ years & $28 \%{ }^{6}$ & hPMS2, TGF $\beta-R I I$ \\
\hline & $<45$ years & $18 \%{ }^{6}$ & \\
\hline \multicolumn{4}{|c|}{ Familial adenomatous polyposis (FAP) (OMIM 175100) } \\
\hline \multirow{2}{*}{\multicolumn{4}{|c|}{$\begin{array}{ll}\text { OMIM web page } & \text { http://www.ncbi.nlm.nih.gov/entrez/dispomim.cgi?id=175100 } \\
\text { Mutation database } & \text { http://perso.curie.fr/Thierry.Soussi/APC.html\#Ancrage2 }\end{array}$}} \\
\hline & http://perso.curie.fr/Thierry.Soussi/APC.html\#Ancrage2 & & \\
\hline \multicolumn{2}{|r|}{ 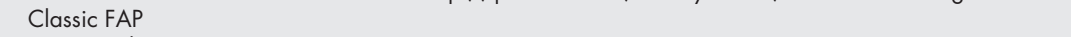 } & $80 \%{ }^{1516}$ & APC \\
\hline \multicolumn{2}{|l|}{ Attenuated FAP } & $<2 \%{ }^{17}$ & APC \\
\hline \multicolumn{4}{|l|}{ Peutz-Jeghers syndrome OMIM 175200} \\
\hline \multirow[t]{3}{*}{ OMIM web page } & http://www.ncbi.nlm.nih.gov/entrez/dispomim.cgi?id=175200 & & \\
\hline & & $20-63 \%^{25-27}$ & STK $11 /$ LKB 1 \\
\hline & & $<5 \%{ }^{36}$ & PTEN \\
\hline \multicolumn{4}{|c|}{ Juvenile polyposis (OMIM 174900 and 601228 ) } \\
\hline \multicolumn{2}{|c|}{ Juvenile polyposis (OMIM 174900) } & $50 \%{ }^{31-34}$ & SMAD4/DPC4 \\
\hline \multicolumn{2}{|c|}{ OMIM web page $\quad$ http://www.ncbi.nlm.nih.gov/entrez/dispomim.cgi?id=174900 } & & \\
\hline \multirow{2}{*}{\multicolumn{2}{|c|}{$\begin{array}{l}\text { Mixed juvenile/adenomatous polyposis (OMIM 601228) } \\
\begin{array}{ll}\text { OMIM web page } & \text { http://www.ncbi.nlm.nih.gov/entrez/dispomim.cgi?id=601228 }\end{array}\end{array}$}} & $\mathrm{N} / \mathrm{K}$ & $6 q$ locus 77 \\
\hline & & & \\
\hline
\end{tabular}


be cumulative over the years of surveillance. Using available data on complications after colonoscopic polypectomy, ${ }^{71-74}$ the perforation rate after polypectomy is 22 (95\% CI 13.8 to 33.3 ) per 10000 and post-polypectomy bleeding occurs in a further 89 (95\% CI 71.5 to 109.5 ) per 10000 . Mortality after polypectomy is $3.9(95 \%$ CI 1.1 to 8.8$)$ per $10000,{ }^{71-74}$ although most fatalities arise in older patients. None the less, it is possible to estimate the cumulative risk of serious complications over 25 years under surveillance based on a polypectomy being carried out at each screening episode. Applying the guidelines and screening intervals described above results in a cumulative risk of $2.8 \%$ for perforation, $11 \%$ for serious bleeding, and $0.05 \%$ for procedure related death.

\section{RECOMMENDATIONS FOR AUDIT}

Audit is an essential component of all aspects of the management of the conditions discussed in this document. Setting up of registries to manage surveillance in individuals from families with dominant cancer syndromes will allow rolling audit of caseload compliance, service delivery, and outcomes. Such audit will inform future management, as randomised trials of surveillance are unlikely. For PJS and JPS, linking of national registries will provide more refined population prevalence estimates. Audit of the prevalence of polyps and cancer at each surveillance episode will provide essential data on age at onset and hence permit more refined estimations of gene penetrance. It will also permit description of genotype phenotype correlations. Gene penetrance and genotype phenotype correlation will inform clinical management by describing the optimal timing and the nature of prophylactic surgery or other protective intervention, such as chemoprevention.

\section{Author's affiliations}

M G Dunlop, Academic Coloproctology, University of Edinburgh, Western General Hospital, Edinburgh EH4 2XU, UK;

Malcolm.Dunlop@hgu.mrc.ac.uk

\section{REFERENCES}

1 Vasen HF, Mecklin JP, Khan PM, et al. The International Collaborative Group on Hereditary Non-Polyposis Colorectal Cancer (ICG-HNPCC). Dis Colon Rectum 1991;34:424-5. (Category: IV)

2 Vasen HF, Watson P, Mecklin JP, et al. New clinical criteria for hereditary nonpolyposis colorectal cancer (HNPCC, Lynch syndrome) proposed by the International Collaborative group on HNPCC Gastroenterology 1999;116:1453-6. (Category: IV)

3 Rodriguez-Bigas MA, Boland CR, Hamilton SR, et al. A National Cancer Institute Workshop on Hereditary Nonpolyposis Colorectal Cancer Syndrome: meeting highlights and Bethesda guidelines. J Natl Cancer Inst 1997;89:1758-62. (Category: IV)

4 Papadopoulos N, Lindblom A. Molecular basis of HNPCC: mutations of MMR genes. Hum Mutat 1997;10:89-99. (Category: Ilb)

5 Peltomaki P, Vasen HF. Mutations predisposing to hereditary nonpolyposis colorectal cancer: database and results of a collaborative study. The International Collaborative Group on Hereditary Nonpolyposis Colorectal Cancer. Gastroenterology 1997;113:1146-58. (Category: IIb)

6 Farrington SM, Lin-Goerke J, Ling J, et al. Systematic analysis of hMSH2 and $\mathrm{hMLHI}$ in young colon cancer patients and controls. Am J Hum Genet 1998;63:749-59. (Category: Ilb)

7 Wijnen JT, Vasen HF, Khan PM, et al. Clinical findings with implications for genetic testing in families with clustering of colorectal cancer. N Engl J Med 1998;339:511-18. (Category: Ilb)

8 Syngal S, Fox EA, Li C, et al. Interpretation of genetic test results for hereditary nonpolyposis colorectal cancer: implications for clinical predisposition testing. JAMA 1999;282:247-53. (Category: Ilb)

9 Liu B, Farrington SM, Petersen GM, et al. Genetic instability occurs in the majority of young patients with colorectal cancer. Nature Medicine 1995; 1:348-52. (Category: Ilb)

10 Vasen HF, Taal BG, Nagengast FM, et al. Hereditary nonpolyposis colorectal cancer: results of long-term surveillance in 50 families. Eur $J$ Cancer 1995;31 A: 1 145-8. (Category: III)

11 Aarnio M, Mecklin JP, Aaltonen LA, et al. Life-time risk of different cancers in hereditary non-polyposis colorectal cancer (HNPCC) syndrome. Int J Cancer 1995;64:430-3. (Category: III)

12 Dunlop MG, Farrington SM, Carothers AD, et al. Cancer risk associated with germline DNA mismatch repair gene mutations. Hum Mol Genet 1997;6:105-10. (Category: Ilb)
13 Bussey HJR. Familial polyposis coli. Family studies, histopathology, differential diagnosis, and results of treatment. Baltimore: Johns Hopkins University Press, 1975. (Category: IV)

14 Bulow S. Familial adenomatous polyposis. Ann Med 1989;21:299_ 307. (Category: III)

15 Wallis YL, Morton DG, McKeown CM, et al. Molecular analysis of the APC gene in 205 families: extended genotype-phenotype correlations in FAP and evidence for the role of APC amino acid changes in colorectal cancer predisposition. J Med Genet 1999;36:14-20. (Category: Ilb)

16 van der Luijt RB, Khan PM, Vasen HF, et al. Molecular analysis of the APC gene in 105 Dutch kindreds with familial adenomatous polyposis: 67 germline mutations identified by DGGE, PTT, and southern analysis. Hum Mutat 1997;9:7-16. (Category: Ilb)

17 Spirio L, Olschwang S, Groden J, et al. Alleles of the APC gene: an attenuated form of familial polyposis. Cell 1993;75:951-7. (Category: IIb)

18 Belchetz LA, Berk T, Bapat BV, et al. Changing causes of mortality in patients with familial adenomatous polyposis. Dis Colon Rectum 1996;39:384-7. (Category: III)

19 Galle TS, Juel K, Bulow S. Causes of death in familial adenomatous polyposis. Scand J Gastroenterol 1999;34:808-12. (Category: III)

20 Bisgaard ML, Fenger K, Bulow S, et al. Familial adenomatous polyposis (FAP): frequency, penetrance, and mutation rate. Hum Mutat 1994;3:121-5. (Category: Ilb)

21 Utsunomiya J, Gocho H, Miyanaga T, et al. Peutz-Jeghers syndrome: its natural course and management. Johns Hopkins Med J 1975;136:71-82. (Category: III)

22 Tomlinson IP, Houlston RS. Peutz-Jeghers syndrome. J Med Genet 1997;34:1007-1 1. (Category: III)

23 Giardiello FM, Welsh SB, Hamilton SR, et al. Increased risk of cancer in the Peutz-Jeghers syndrome. N Engl J Med 1987;316:1511-14. (Category: III)

24 Spigelman AD, Murday V, Phillips RK. Cancer and the Peutz-Jeghers syndrome. Gut 1989;30:1588-90. (Category: III)

25 Hemminki A, Markie D, Tomlinson I, et al. A serine/threonine kinase gene defective in Peutz-Jeghers syndrome. Nature 1998;391:184-7 (Category: Ilb)

26 Boardman LA, Couch FJ, Burgart LJ, et al. Genetic heterogeneity in Peutz-Jeghers syndrome. Hum Mutat 2000;16:23-30. (Category: Ilb)

27 Westerman AM, Entius MM, Boor PP, et al. Novel mutations in the LKB 1/STK 11 gene in Dutch Peutz-Jeghers families. Hum Mutat 1999;13:476-81. (Category: Ilb)

28 Nugent KP, Talbot IC, Hodgson SV, et al. Solitary juvenile polyps: not a marker for subsequent malignancy. Gastroenterology 1993;105:698700. (Category: III)

29 Howe JR, Mitros FA, Summers RW. The risk of gastrointestinal carcinoma in familial juvenile polyposis. Ann Surg Oncol 1998;5:751-6. (Category: Ilb)

30 Scott-Conner CE, Hausmann M, Hall TJ, et al. Familial juvenile polyposis: patterns of recurrence and implications for surgical management. J Am Coll Surg 1995;181:407-13. (Category: III)

31 Howe JR, Roth S, Ringold JC, et al. Mutations in the SMAD4/DPC4 gene in juvenile polyposis. Science 1998;280:1086-8. (Category: Ilb)

32 Roth $S$, Sistonen $P$, Salovaara R, et al. SMAD genes in juvenile polyposis. Genes ChromosomesCancer 1999;26:54-61. (Category: IIb)

33 Woodford-Richens K, Bevan S, Churchman M, et al. Analysis of genetic and phenotypic heterogeneity in juvenile polyposis. Gut 2000;46:656-60. (Category: Ilb)

34 Yoon KA, Ku JL, Choi HS, et al. Germline mutations of the STK 11 gene in Korean Peutz-Jeghers syndrome patients. Br J Cancer 2000;82: 1 403-6. (Category: IIb)

35 Huang SC, Chen CR, Lavine JE, et al. Genetic heterogeneity in familial juvenile polyposis. Cancer Res 2000;60:6882-5. (Category: Ilb)

36 Olschwang S, Serova-Sinilnikova OM, Lenoir GM, et al. PTEN germ-line mutations in juvenile polyposis coli. Nat Genet 1998;18:12-14. (Category: IIb)

37 Kee F, Collins BJ. How prevalent is cancer family syndrome? Gut 1991;32:509-12. (Category: Ilb)

38 Mecklin JP, Jarvinen HJ, Hakkiluoto A, et al. Frequency of hereditary nonpolyposis colorectal cancer. A prospective multicenter study in Finland. Dis Colon Rectum 1995;38:588-93. (Category: III)

39 ponz de Leone $M$, Pedroni $M$, Benatti $P$, et al. Hereditary colorectal cancer in the general population: from cancer registration to molecula diagnosis. Gut 1999;45:32-8. (Category: III)

40 Aaltonen LA, Salovarra R, Kristo P, et al. Incidence of hereditary nonpolyposis colorectal cancer and the feasibility of molecular screening for the disease. N Engl J Med 1998;338:1481-7. (Category: Ilb)

41 Dunlop MG, Farrington SM, Nicholl I, et al. Population carrier frequency of hMSH2 and hMLH1 mutations. Br J Cancer 2000;83:1643-5. (Category: Ilb)

42 Houlston RS, Collins A, Slack J, et al. Dominant genes for colorectal cancer are not rare. Ann Hum Genet 1992;56:99-103. (Category: Ilb)

43 Bulow S, Bulow C, Nielsen TF, et al. Centralized registration, prophylactic examination, and treatment results in improved prognosis in familial adenomatous polyposis. Results from the Danish Polyposis Register. Scand J Gastroenterol 1995;30:989-93. (Category: III)

44 Dajani YF, Kamal MF. Colorectal juvenile polyps: an epidemiological and histopathological study of 144 cases in Jordanians. Histopathology 1984;8:765-79. (Category: III)

45 ASCO. Statement of the American Society of Clinical Oncology: genetic testing for cancer susceptibility, Adopted on February 20, 1996. J Clin Oncol 1996;14:1730-6. (Category: IV) 
46 Aitken J, Bain C, Ward M, et al. How accurate is self-reported family history of colorectal cancer? Am J Epidemiol 1995;141:863-71. (Category: Ilb)

47 Kerber RA, Slattery ML. Comparison of self-reported and database-linked family history of cancer data in a case-control study. Am J Epidemiol 1997;146:244-8. (Category: Ilb)

48 Rodriguez-Bigas MA, Lee $\mathrm{PH}, \mathrm{O}^{\prime}$ Malley L, et al. Establishment of a hereditary nonpolyposis colorectal cancer registry. Dis Colon Rectum 1996;39:649-53. (Category: IV)

49 Myrhoi T, Bernstein I, Bisgaard ML, et al. The establishment of an HNPCC register. Anticancer Res 1994;14:1647-50. (Category: IV)

50 Madlensky L, Berk TC, Bapat BV, et al. A preventive registry for hereditary nonpolyposis colorectal cancer. Can J Oncol 1995;5:355-60. (Category: IV)

51 Jarvinen HJ, Aarnio M, Mustonen H, et al. Controlled 15-year trial on screening for colorectal cancer in families with hereditary nonpolyposis colorectal cancer. Gastroenterology 2000;1 18:829-34. (Category: Ilb)

52 Vasen HF, Mecklin JP, Watson P, et al. Surveillance in hereditary nonpolyposis colorectal cancer: an international cooperative study of 165 families. The International Collaborative Group on HNPCC. Dis Colon Rectum 1993;36:1-4. (Category: III)

53 Myrhoi T, Bisgaard ML, Bernstein I, et al. Hereditary non-polyposis colorectal cancer: clinical features and survival. Results from the Danish HNPCC register. Scand J Gastroenterol 1997;32:572-6. (Category: III)

54 Vasen HF, Wijnen JT, Menko FH, et al. Cancer risk in families with hereditary nonpolyposis colorectal cancer diagnosed by mutation analysis. Gastroenterology 1996;1 10:1020-7. (Category: Ilb)

55 Aarnio M, Sankila R, Pukkala E, et al. Cancer risk in mutation carriers of DNA-mismatch-repair genes. Int J Cancer 1999;81:214-18. (Category: III)

56 Vasen HF, Nagengast FM, Khan PM. Interval cancers in hereditary non-polyposis colorectal cancer (Lynch syndrome). Lancet 1995;345: 1 183-4. (Category: III)

57 Lynch HT, Smyrk TC, Watson P, et al. Genetics, natural history, tumor spectrum, and pathology of hereditary nonpolyposis colorectal cancer: an updated review. Gastroenterology 1993;104:1535-49. (Category: III)

58 Church JM. Prophylactic colectomy in patients with hereditary nonpolyposis colorectal cancer. Ann Med 1996;28:479-82. (Category: IV)

59 Rodriguez-Bigas MA, Vasen HF, Pekka-Mecklin J, et al. Rectal cancer risk in hereditary nonpolyposis colorectal cancer after abdominal colectomy. International Collaborative Group on HNPCC. Ann Surg 1997;225:202-7. (Category: III)

60 Morton DG, Macdonald F, Haydon J, et al. Screening practice for familial adenomatous polyposis: the potential for regional registers. $\mathrm{Br} J$ Surg 1993;80:255-8. (Category: III)

61 de Cosse J, Bulow S, Neale K, et al. Rectal cancer risk in patients treated for familial adenomatous polyposis. The Leeds Castle Polyposis Group. Br J Surg 1992;79:1372-5. (Category: III)
62 Nugent KP, Phillips RK. Rectal cancer risk in older patients with familial adenomatous polyposis and an ileorectal anastomosis: a cause for concern. Br J Surg 1992;79: 1204-6. (Category: III)

63 Debinski HS, Love S, Spigelman AD, et al. Colorectal polyp counts and cancer risk in familial adenomatous polyposis. Gastroenterology 1996;1 10:1028-30. (Category: Ilb)

64 Vasen HF, van der Luijt RB, Slors JF, et al. Molecular genetic tests as a guide to surgical management of familial adenomatous polyposis. Lancet 1996;348:433-5. (Category: Illb)

65 Bulow C, Vasen $H$, Jarvinen $H$, et al. lleorectal anastomosis is appropriate for a subset of patients with familial adenomatous polyposis. Gastroenterology 2000;1 19:1454-60. (Category: III)

66 Vasen HF, van BM, Buskens $E$, et al. A cost-effectiveness analysis of colorectal screening of hereditary nonpolyposis colorectal carcinoma gene carriers. Cancer 1998;82:1632-7. (Category: Ilb)

67 Spigelman AD, Talbot IC, Penna C, et al. Evidence for adenoma-carcinoma sequence in the duodenum of patients with familial adenomatous polyposis. The Leeds Castle Polyposis Group (Upper Gastrointestinal Committee). J Clin Pathol 1994;47:709-10. (Category: Gas

68 Spigelman AD, Williams CB, Talbot IC, et al. Upper gastrointestinal cancer in patients with familial adenomatous polyposis. Lancet 1989;ii:783-5. (Category: III)

69 Vasen HF, Bulow S, Myrhoi T, et al. Decision analysis in the management of duodenal adenomatosis in familial adenomatous polyposis. Gut 1997;40:716-19. (Category: Ilb)

70 Penna C, Phillips RK, Tiret E, et al . Surgical polypectomy of duodenal adenomas in familial adenomatous polyposis: experience of two European centres. Br J Surg 1993;80:1027-9. (Category: III)

71 Waye JD, Lewis BS, Yessayan S. Colonoscopy: a prospective report of complications. J Clin Gastroenterol 1992;15:347-51. (Category: Ilb)

72 Kewenter J, Brevinge H. Endoscopic and surgical complications of work-up in screening for colorectal cancer. Dis Colon Rectum 1996;39:676-80. (Category: III)

73 Jorgensen OD, Kronborg O, Fenger $C$. The Funen Adenoma Follow-up Study. Incidence and death from colorectal carcinoma in an adenoma surveillance program. Scand J Gastroenterol 1993;28:869-74. (Category: Illb)

74 Puchner R, Allinger S, Doblhofer F, et al. [Complications of diagnostic and interventional colonoscopy]. Wien Klin Wochenschr 1996; 108: 142-6. (Category: III)

75 Liu B, Parsons R, Papadopoulos N, et al. Analysis of mismatch repair genes in hereditary non-polyposis colorectal cancer patients. Nature Medicine 1996;2:169-74. (Category: Ilb)

76 Wijnen J, Khan PM, Vasen H, et al. Hereditary nonpolyposis colorectal cancer families not complying with the Amsterdam criteria show extremely low frequency of mismatch-repair-gene mutations. Am J Hum Genet 1997;61:329-35. (Category: Ilb)

77 Thomas HJ, Whitelaw SC, Cottrell SE, et al. Genetic mapping of hereditary mixed polyposis syndrome to chromosome 6q. Am J Hum Genet 1996;58:770-6. (Category: Ilb) 